\title{
WHR (Waste Heat Technology) Method in Tri-generation Model
}

\author{
Imrich Discantiny
}

COMTHERM s.r.o., Palatínova 39, Komárno 94501, Slovak Republic

\begin{abstract}
This paper is focused on description of cool production in using WHR (Waste Heat Technology) Technology—a new method of centralized production of heat by using the waste heat from generated exhaust gas, which has been in 2009 developed and operated by companies HELORO s.r.o. and COMTHERM s.r.o.
\end{abstract}

Key words: NG (natural gas), GB (gas boiler), CHP (combined heat \& power), CHPC (combined heat \& power \& cool), CGU (co-generation unit), ABSU (absorption unit), TC (thermal condenser), HE1, HE2 (heat exchanger).

\section{Background/Introduction}

This Abstract is focused on description of cool production in using WHR (Waste Heat Technology) Technology — a new method of centralized production of heat by using the waste heat from generated exhaust gas, which has been in 2009 developed and operated by companies HELORO s.r.o. and COMTHERM s.r.o. In 2013, the technology was combined with the utilisation of renewable energy sources-heat emissions from surrounded facilities, geothermal well, located on the operations site, as well as installed solar collectors. As of 2014 the companies focused on the research and development in the field of tri-generation, i. e. the highly efficient combined production of CHPC (electricity, heat and cooling), connecting a hot water absorption chiller unit to CHP (combined heat \& power) technology in combination with WHR technology. The new advanced and progressively developing processes in the segment of highly efficient combined electricity (CHP) and heat production enhance the living standard, and provide a higher comfort of living in apartment, administrative and production buildings and facilities. Simultaneously with such growing segment grows the

\footnotetext{
Corresponding author: Imrich Discantiny, Dipl. Ing., research field: renevable energies. E-mail: discantiny@comtherm.sk.
}

importance of a flexible production of cold.

\section{Problem}

Operation of installed high efficient CHP units must be mostly interrupted during the summer period.

Our generation have more actual environmental problems, i.a.:

- To fix climate change;

- To cut greenhouse gases by $60 \%$ by 2050 ;

- To build a pollution-free heat \& power plants;

- To sort out a new way of getting energy;

- The needs in the cool production are continuously growing;

- There is no other possible way of doing that except through renewables. So we seek new;

- Environmental solutions and alternative energy sources.

\section{WHR Technology Description}

The technological WHR solution depends on the method and system of flue gas processing for the flue gas that is generated through the combustion of gaseous fuel (NG (natural gas), methane, biogas, and geothermal gas) in the heat source. The solution defines more effective and non-traditional usage of gaseous fuel for heating, where the flue gas is further processed in order to extract from it additional usable 
heat, with the potential subsequent elimination of $\mathrm{CO}_{2}$ from it in the separation module.

\subsection{Current Deployment of Condensing Boilers in Operations}

Gas boilers use the condensation heat, and they operate at the lower interval of heating medium temperatures $\left(35^{\circ} \mathrm{C}-40{ }^{\circ} \mathrm{C}\right)$ in the recurrent sleeve and significantly lower than the dew point temperature, which is approximately $57^{\circ} \mathrm{C}$. Hence such solution is not applicable in case of a central heating, where the heat production plant operates with a much hotter heating medium in the recurrent sleeve $\left(55^{\circ} \mathrm{C}\right)$, and at such temperature one cannot reach the condensation of the flue gas (neither in case of heat exchangers with large surfaces) through the direct deployment of a recurrent sleeve. The model of thermal condensers connection set-up, which drains the flue gas from the heat source, has an additional disadvantage in that the flue gas cannot be cooled down below the recurrent sleeve temperature, which thus prevents the effective condensation of water vapours.

The partial condensation starts at the flue gas temperatures below $70{ }^{\circ} \mathrm{C}$, however an efficient use of the specific latent heat starts only at the temperature below dew point. Cooling of the flue gas below dew point temperature causes condensation of the water vapour and the release of condensation heat. The aim of the essential WHR technology model is to provide a very intensive flow of water vapour condensation. The more efficient is the cooling of flue gases and the course of condensation, the higher and the quantity of residual heat that could be used for heating; whereas the higher degree of flue gas cooling, the more efficient will be the separation of $\mathrm{CO}_{2}$ in the separator device. [1]

The processing of the flue gas waste heat using WHR technology eliminates the shortcomings of the existing status of hardware, where the heat source transmits heat to the heating medium in the exit sleeve, and the heating medium returns through the recurrent sleeve back to the heat source.

\subsection{WHR Method in Tri-generation Model}

The boiler room set-up clearly shows that the natural gas medium is carried into the cascade-connected set of heating boilers, and into the heat source No. 2-CGU (co-generation unit), which generates with added value the required electric energy needed for the operation of the boiler-room equipment, including the operation of the heat pump drive (see Fig. 1).

\subsubsection{HE1 (Heat Exchanger)}

The flue gas generated through the combustion of gaseous fuel in the heat sources (in the heating boiler/120 ${ }^{\circ} \mathrm{C}$ and in CGU/170 ${ }^{\circ} \mathrm{C}$ ) are through the joint flue gas piping connected to the HE1 (of gas/liquid type), where takes place the transfer of heat into the heating medium at temperatures above the recurrent sleeve temperature. The HE1 act as a source of heat $/ 70{ }^{\circ} \mathrm{C}$ for a secondary circuit flowing to the boilers, which acts as pre-heating module for the recurrent circuit (from the temperature $70 / 60{ }^{\circ} \mathrm{C}$ ).

\subsubsection{TC (Thermal Condenser)}

TC is a specific type of heat exchanger, which is adjusted to cope with the waste heat from the flue gas together with the condensation heat from the water vapours.

In the course of this process, the flue gas cools down to a temperature that is lower than the flue gas dew point, and at the same time lower than the temperature within the heating medium in the recurrent sleeve. At the same time, the cooling circuit of the thermal condenser will not be directly interconnected with the heating medium recurrent sleeve. [1]

The process of cooling down to the temperature $/ 25^{\circ} \mathrm{C}$ is permanent, and it is accompanied by a high degree of water vapour condensation, which causes drying of the flue gas, and it has three, mutually combinable advantages - the process is accompanied by the release of condensation heat, and by the release of $\mathrm{H}_{2} \mathrm{O}$ with a significant share of $\mathrm{NO}_{\mathrm{x}}$ emissions into the sewage, and at the same time it is possible to arrange at the next downstream stage a separation of $\mathrm{CO}_{2}$ in the separation equipment. 


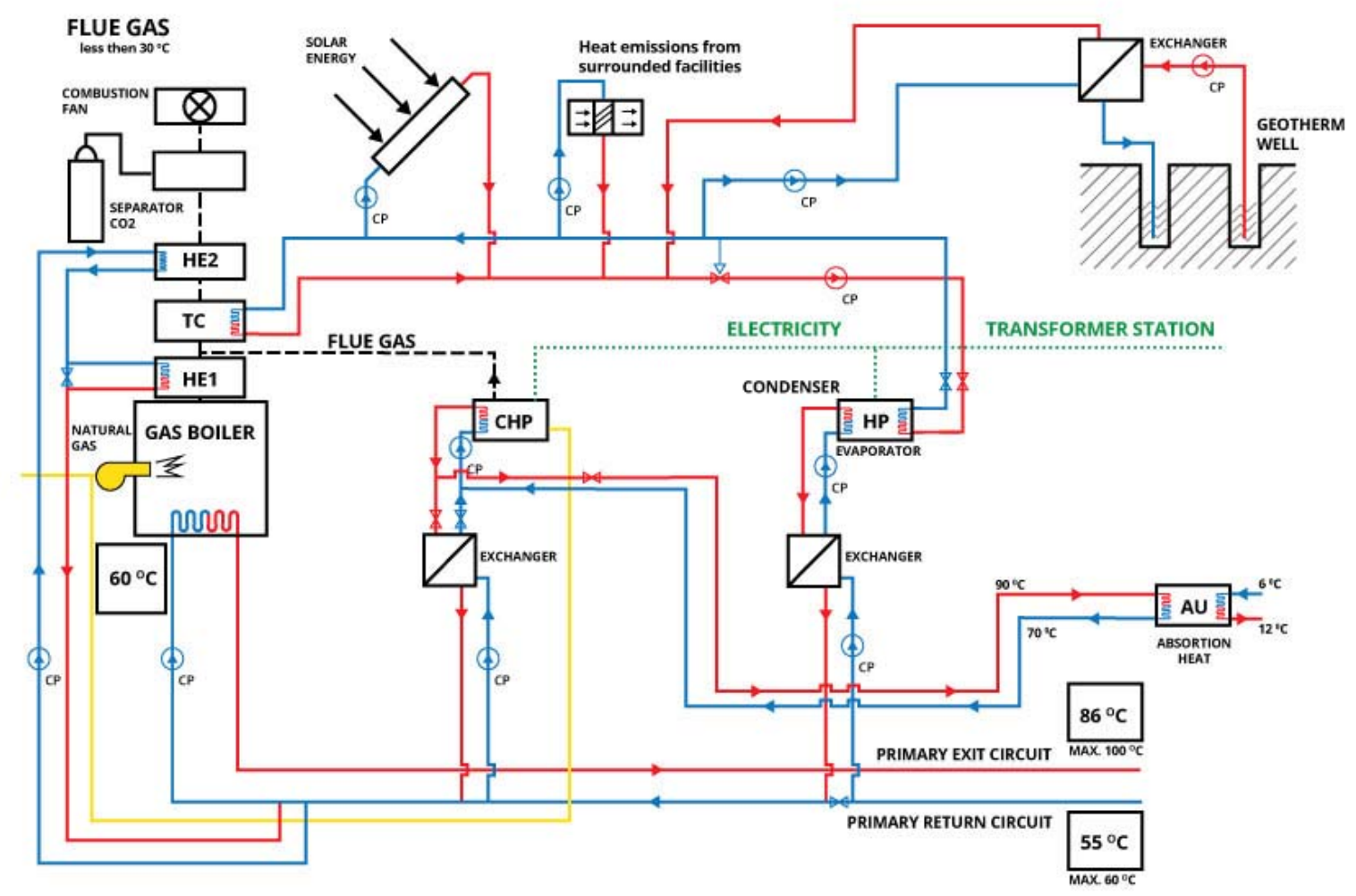

Fig. 1 General scheme of the boiler house.

\subsubsection{HP (Heat Pump)}

The source of heat for the heat pump is the TC (thermal condenser), connected to a separate circuit, within which is the low potential heat pumped to a higher temperature, utilisable in the heating system. Since the initial exit temperatures $10 / 31{ }^{\circ} \mathrm{C}$ would normally not be suitable for start-up of the HP, this closed circuit will be complemented by adding a 3WV (three-way valve) and a CP (circulating pump), which would allow regulation of the heat-carrying medium input also from other sources of low-potential heat (solar panels, well, ...). Temperature falling gradient directly at the entry to this heat pump circuit is $10 / 18{ }^{\circ} \mathrm{C}$, and in case of such temperatures, we see the benefits of the proposed connection set-up, when the TC cooling sleeve is fed with the $10^{\circ} \mathrm{C}$ heat-carrying medium, which guarantees a sufficient temperature gradient that cannot be reached using a heating medium with the temperature $/ 50{ }^{\circ} \mathrm{C}$. [1]

In energy sector, owing to their high performance number COP (Coefficient of Performance) (3.8-4.5), the heat pumps are becoming an important technological component, increasing the energy efficiency to more than $100 \%$. In particular, in case of a complex WHR technological system this total efficiency figure reaches $115 \%$ (as a mix of $30 \%$ power generation efficiency, and $85 \%$-heat production efficiency).

\subsubsection{HE2 (Heat Exchanger)}

Within the heat exchanger HE2 (of gas/liquid type) takes place the partial pre-heating of cooled liquids (although without $\mathrm{NO}_{\mathrm{x}}$ emissions) to a temperature tightly above the dew point, in order to avoid an unwanted condensation of water residues in the chimney liner.

Substantial degree of $\mathrm{CO}_{2}$ separation takes place in 
the separator device, mounted on the extruding part of the heat exchanger HE2, which operates based on the cooling principle. [1]

Unused volume of flue gases $\left(25^{\circ} \mathrm{C}\right)$ is evacuated through flue ventilator in a dry state (approximately $30-40{ }^{\circ} \mathrm{C}$ ) into the chimney.

3.2.5 Tri-generation, Connection of AU (Absorption Unit) to CHP \& HP System

WHR technology operates as a tri-generation involving the process of cooling within the cogeneration unit's heat-generating circuit, which could be arranged in two ways:

Through connection to the heat exchanger in the heat-generating circuit (of liquid/liquid type), with the follow up transfer of heat for pre-heating to the heating medium recurrent sleeve via heat exchanger, at the same time is the CHP unit cooled down.

Through connection of an AU (absorption unit) to the heat-generating circuit, where the produced heat from CGU is effectively converted to cold $\left(6^{\circ} \mathrm{C}-12^{\circ} \mathrm{C}\right)$ at the temperature regime $90 / 70^{\circ} \mathrm{C}$, where as the waste water from $\mathrm{AU}\left(40{ }^{\circ} \mathrm{C}\right)$ can be used to effectively pre-heat the water in the hot service water production step.

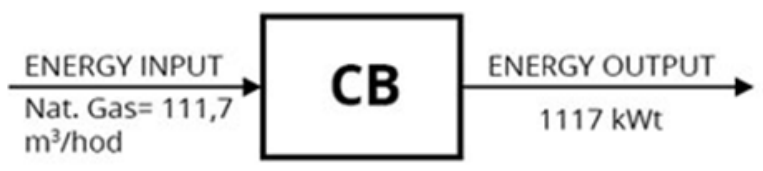

\section{Consumption of Input Energy Carrier and Costs Savings}

The Fig. 2 and Table 1 indicate the NG consumption savings of a system, combining CHP simultaneously with heat pumps versus gas-fuelled condensing boiler. [4]

\section{Energy Savings Summary}

The $60{ }^{\circ} \mathrm{C}$ pre-heated medium enters the gas boiler (see Fig. 1). As a simplification we can say that we have saved energy that would be needed to raise the temperature of the heating medium from $55{ }^{\circ} \mathrm{C}$ to $60{ }^{\circ} \mathrm{C}$. The Fig. 2 and Table 1 [4] indicate the NG consumption savings of a system, combining CHP simultaneously with heat pumps versus gas-fuelled condensing boiler. The Fig. 3 indicates energy diagram of CHPC (combined heat, power \& cool) \& WHR energy system. [3]

\section{Pay-back Period of Investment}

It depends on the existing system, industry segment, and the consumption of heat and electricity. According to our experience, the payback period has never exceeded 4 years.

\section{Connection scheme for combined configuration:}

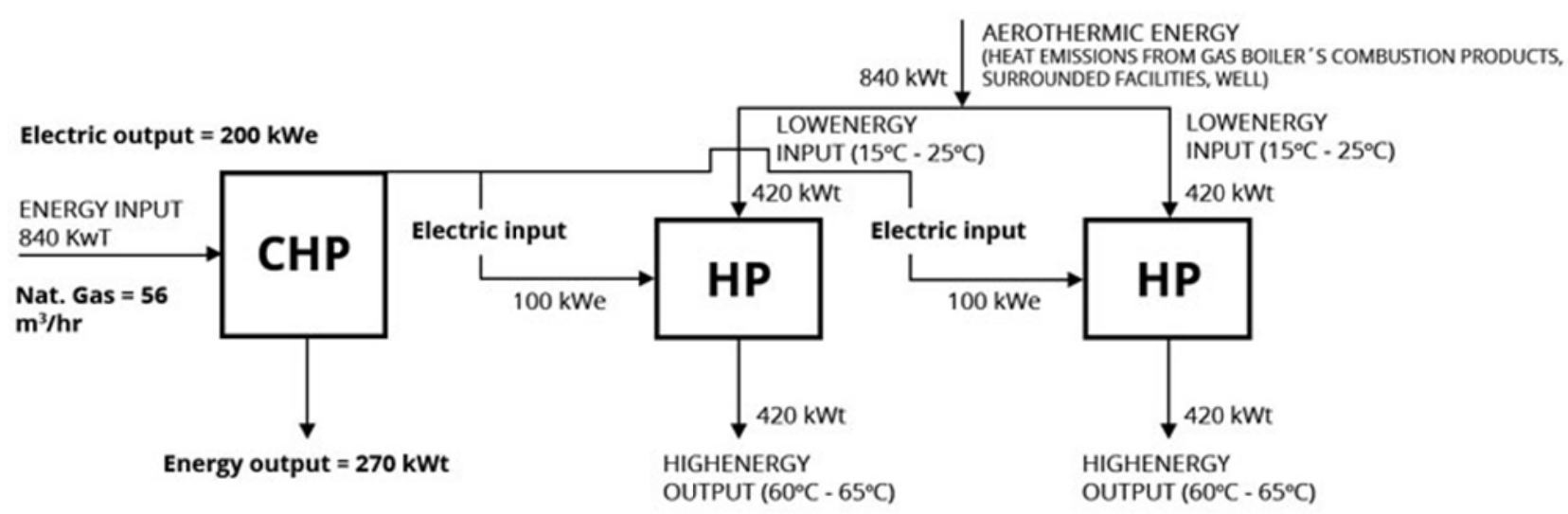

Fig. 2 Comparative diagram of natural gas consumption. [3] 


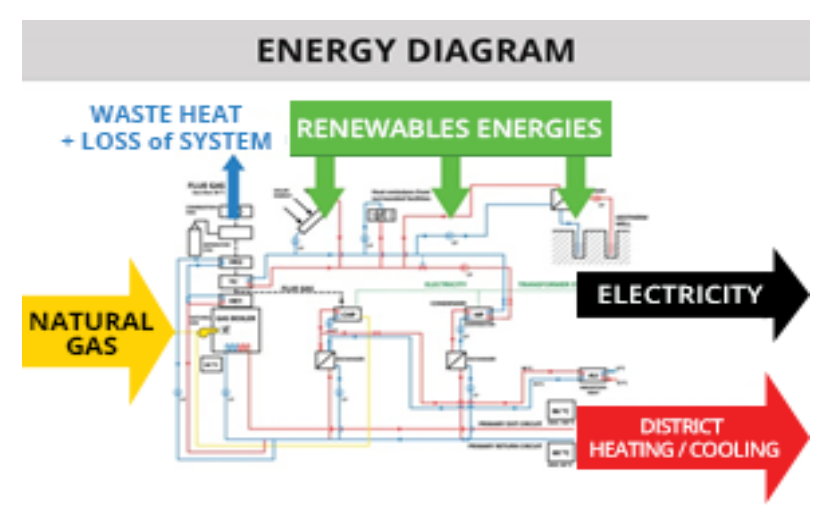

Fig. 3 Energy diagram.

Table 1 Evaluation of Natural Gas Costs Savings. [4]

\begin{tabular}{ll}
\hline Assumed consumption of CB & $11,170 \mathrm{~m}^{3}$ \\
\hline Consumption of combined system CHP \& HP & $56 \mathrm{~m}^{3} / \mathrm{hr}$ \\
HG saving/hr & $557 \mathrm{~m}^{3} / \mathrm{hr}$ \\
Annual NG saving ( $8000 \mathrm{hr}$ ) & $445,600 \mathrm{~m}^{3}$ \\
Financial calculation (approx.) & 147,000 eur \\
\hline
\end{tabular}

\section{Conclusions}

The industrial applicability of the basic WHR technology model in combination with the absorption cooling is self-evident. Through 3-year operation in real environment in the gas-operated heat plant we have demonstrated the possibility of industrial and recurrent utilisation of waste heat from the heat source-generated flue gas, with the spin-off benefit of separation of $\mathrm{NO}_{\mathrm{x}}$ and $\mathrm{CO}_{2}$ emissions from the flue gas. In addition to a significant environmental benefits the connection set-up has demonstrated also the system's enhanced energy efficiency, and an improved efficiency of the gaseous fuel.

This modification opens new and effective possibilities of enhanced energy efficiency of heat sources with the subsequent reduction of annual operating costs of thermal management of buildings, building complexes etc., since during the summer period all installed technology remains operating.

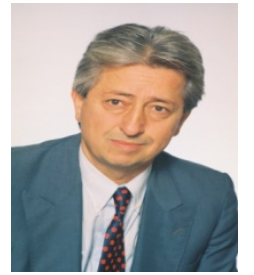

Author

Imrich Discantiny

Senior Consultant

COM-therm s.r.o.

Heloro s.r.o.

Komárno, Slovak Republic

E-mail: discantiny@comtherm.sk
Tri-generation develops a possibility to reduce the economic intensity of all-season generation of heat and cold. It becomes an actual and attractive technology for the solution of communal needs, which increasingly require more and more of cooling. In addition to standard air-conditioning solutions, nowadays we meet more and more often the engineering networks with complete cold distribution networks, and/or cold distribution piping, either in urban quarters or even in the whole cities. One can assume that in several years the production of cold will become comparable to the production of electricity and heat. The current trend has been caused by several factors:

Development of an architecture with glass-covered facades of new buildings.

Appliances operated in individual rooms generate certain heat output (servers, fridges, as well as other daily appliances)

For these reasons, all around the world, the production of cold marks a fast growth. In addition to standard air-conditioning solutions, nowadays we meet more and more often the engineering networks with complete cold distribution networks, and/or cold distribution piping, either in urban quarters or even in the whole cities.

\section{References}

[1] COM-therm, s.r.o., Bratislava/Heloro, s.r.o. Utility Model 300020 DE 1. Bratislava: COM-therm, s.r.o., Bratislava/Heloro, s.r.o.

[2] Industrial Property Office. 2011. The basic Utility Model Nr. SK 6120 Y1. Slovak Republic: Banská Bystrica.

[3] Discantiny, I. 2014. WHR Innovative Technology-Intelligent Energies, Gas for Energy. München: DIV Deutscher Industrieverlag GmbH.

[4] Discantiny, I. 2015. New Technology of the Use of Waste Heat from Heat Source (Nová technológia využitia odpadového tepla). SLOVGAS: Slovak Gas \& Oil Association. (in press) 